Bangladesh J. Bot. 48(4): 1091-1097, 2019 (December)

\title{
IMPACT OF HALOPRIMING ON FOUR WHEAT (TRITICUM AESTIVUM L.) CULTIVARS OF BALOCHISTAN UNDER SALINE CONDITIONS
}

\author{
Summi Buzdar, Ayesha Mushtaq, Sabeena Rizwan ${ }^{l}$, Uzma Jabeen, Farrukh \\ Bashir, Farhat Safdar, Mehnaz Baloch, Muzaffar Khan, \\ M Aamir Razaq ${ }^{1}$ and NaEem Shahwani ${ }^{2 *}$
}

Sardar Bahadur Khan Women's University, Quetta, Pakistan

Keywords: Halopriming, Hydropriming, Cultivars, Silicon, Saline

\begin{abstract}
Priming effect of silicon sources (silica gel and sodium silicate) on the seeds of four wheat cultivars of Balochistan was studied to determine their effectiveness in increasing relative salt tolerance. The study depicts that all priming treatments of silicon sources (except sodium silicate $2 \%$ ) enhanced germination and reduced mean germination time (MGT) of seeds in comparison to the control i.e. hydropriming. After germination, the young seedlings were grown in hydroponics in Hoagland's culture solution under controlled conditions in non-saline and saline $(100 \mathrm{mM} \mathrm{NaCl})$ environments. All the growth parameters (root and shoot length, fresh and dry weights of plants and chlorophyll content of leaves) severely reduced in hydroprimed seeds under saline environments, although increased by priming seeds with silicon sources. Thus silica compounds have potential effects to break the seed dormancy and improve the growth of wheat under salinity stress.
\end{abstract}

\section{Introduction}

Agriculture is the main source of Pakistan's economy. The food demand of over growing population can be met by increasing wheat production (Jamal et al. 2011). Bread wheat is the most important crop in irrigation systems of all provinces of Pakistan. Major causes of shortage of wheat production in Balochistan are limited annual rain fall, low and high extremes of temperature, desiccating winds during grain formation and salinity. Salinity is one of the major problems in arid and semiarid areas of Balochistan (Jahangir et al. 2013). Soil salinity prohibited the uptake of beneficial soil nutrients in plant cells and as a result damage plant structure by upsetting metabolic processes (Munns and Tester 2008). Wheat plants tolerate salt stress moderately but grain production is considerably reduced in soils having over $100 \mathrm{mM} \mathrm{NaCl}$ or about $10 \mathrm{dS} / \mathrm{m}$. It is found that $50 \%$ of grain yield suffers in wheat starting at $6 \mathrm{dS} / \mathrm{m}$. Salt stress tolerance has been revealed to differ over wheat growth stages (Yildirim et al. 2015). Salinity badly affects approximately all the stages of growth and development such as germination, seedling growth and vigour, vegetative growth, flowering and fruit set, ultimately causing lower economic yield and also quality of production (Afzal et al. 2007). Therefore, extensive research is required on the production of resistant wheat varieties for salt stress conditions of Balochistan. Seed priming is one of the methods to produce salt tolerant species (Dianati and Behtari 2017). It is a type of seed preparation in which seeds are pre-soaked before planting. Seed priming is an easy, successful, and low cost approach for enhancement of seed germination, early seedling development, and yield under stressed and non-stressed environmental conditions. Priming of seeds with silicon is one of the major techniques, which can improve biotic and abiotic stress resistance in plants (Ahmed et al. 2016). Although silicon found to be an important mineral element but very little work has been done on its priming applications on seeds of wheat (Triticum

*Author for correspondence: <theonlynaeem@gmail.com>. ${ }^{1}$ PCSIR Laboratory, Quetta, Pakistan. ${ }^{2}$ Balochistan University of Information Technology, Engineering \& Management Sciences, Quetta, Pakistan. 
aestivum L.). Therefore, the present work was aimed to test the effect of wheat (Triticum aestivum L.) seed priming with silicon sources i.e. silica gel and sodium silicate on its germination and further its growth in hydroponic culture system under controlled environmental conditions in the presence and absence of salt stress.

\section{Materials and Methods}

Seeds of four indigenous wheat (Triticum aestivum L.) cultivars of Balochistan, two salt resistant cultivars i.e. Zardana and Zarlashta and two salt sensitive cultivars i.e. Sariab and Pirsabaq were collected from the Agriculture Research Institute (ARI), Sariab Road, Quetta, Pakistan. The experiment was conducted in the Stress-Physiology Lab of Biotechnology, BUITEMS (Balochistan University of Information Technology, Engineering and Management Sciences), Quetta in $1^{\text {st }}$ week of April 2017. The two different halopriming materials used in the study were sodium silicate $\left[\mathrm{Na}_{2} \mathrm{SiO}_{3}\right]$ and silica gel $\left[\mathrm{SiO}(\mathrm{OH})_{2}\right]$. For each priming source, primary solution with $1 \%$ and $2 \%$, respectively was prepared to use in this experimentation. All the treatments were compared with the control, in which each variety was primed using distilled water (hydropriming) only (Mukhtar et al. 2016). One hundred healthy seeds of each variety were soaked for $24 \mathrm{hrs}$ in the distilled water for the control, while in silica gel $1 \%(1 \mathrm{~g} / 100 \mathrm{ml})$, silica gel $2 \%(2 \mathrm{~g} / 100 \mathrm{ml})$, sodium silicate $1 \%(1 \mathrm{~g} / 100 \mathrm{ml})$, and sodium silicate $2 \%(2 \mathrm{~g} / 100 \mathrm{ml})$ separately for treatments.

Germination potential of wheat seeds were noted in accordance with International rule of seed testing (ISTA 1935). Twenty seeds of each cultivar were germinated in $12 \mathrm{~cm}$ diameter Petri dishes in dark at $25^{\circ} \mathrm{C}$ in incubator (Afzal et al. 2006). The replicates of wheat seeds were allowed to germinate on water soaked paper towel. The paper towel seeds were kept in an incubator in order to avoid loss of moisture. Counting of germinated seeds were made after every $24 \mathrm{hrs}$ starting from the first day of imbibitions and ended after 5th day when maximum germination was obtained. Germination percentage (Equation 1) and mean germination time (Equation 2) was determined following Ellis and Robert equation (1980) (Solatni et al. 2012).

Final germination percentage $=($ No. of germinated seeds/Total No. of seeds soaked $) \times 100 \quad$ (Eq. 1)

Mean germination time $=\sum \mathrm{Dn} / \sum \mathrm{n} \quad$ (Eq. 2)

$\mathrm{n}=$ The number of seeds, that germinated on day $\mathrm{D} . \mathrm{D}=$ the number of days counted from the 1 st day of germination.

After 10th day, the young seedlings were transferred to the hydroponic tanks under controlled conditions in Stress-Physiology Lab of Biotechnology, BUITEMS. Half of the control seedlings (hydroprimed) and silicon treated (haloprimed) were transferred in hydroponic tanks containing seven liters of water and one fourth strength of Hoagland's nutrient solution under non-saline condition while other half of seedlings were transferred to hydroponic tanks containing Hoagland's nutrient solution plus salt stress with $100 \mathrm{mM} \mathrm{NaCl}$. In hydroponic tanks, seedlings were supported by styrofoam sheet floating on the water surface. In all the treatments, the solutions were continuously aerated with aquarium pumps. $\mathrm{pH}$ in all of the cases was checked and adjusted to 6.0 with $1 \mathrm{~N} \mathrm{NaOH}$ or $\mathrm{HCl}$. The hydroponic tanks were placed in BUITEMS Stress Lab under controlled night-day timings, with a period of $8 \mathrm{hrs}$ of darkness and $16 \mathrm{hrs}$ of light and with controlled temperature $\left(25 / 18^{\circ} \mathrm{C}\right.$ day/night) and light (800 luxes). The nutrient solution was replaced weekly. After appearance of $2 \mathrm{nd}$ leaf $100 \mathrm{mM} \mathrm{NaCl}$ was added in the saline treatments. The young seedlings were allowed to grow in the above-mentioned conditions for 60 days. At the end the growth parameters (root and shoot length, fresh and dry weight of plant and chlorophyll content of leaves) were determined and data were statistically analyzed (Mushtaq et al. 2017). 


\section{Results and Discussion}

The results of the current study reveals that all priming treatments of silicon sources (except sodium silicate $2 \%$ ) enhanced final germination percentage (FGP) and reduced mean germination time (MGT) of seeds in comparison to control i.e. hydropriming (Table 1). Similarly the priming treatments (water and sodium silicate 2\%) having highest MGT (1.6) which reflects their slow germination. The results of the present study collaborates with the results reported by Mushtaq et al (2017) in the increase of germination and decrease in MGT of wheat seeds by priming in silica nanoparticles treatments. The study also affirmed that hydropriming improved the seed germination rate to a lesser extent as compared to seed priming with sodium silicate which agrees with the work of Hameed et al. (2013). Maghsoudi and Emam (2016) also stated similar results that priming of wheat seeds with sodium silicate reduced mean germination time and increase germination rate under stress and non- stress conditions. The above observations strengthen the view that seed priming with silicon sources (silica gel and sodium silicate) can be an economic and effective way for improving the seed germination and for breaking seed dormancy. In addition, the seeds pre-chilled in silicon sources have shown better growth and were able to tolerate salt stress throughout this research.

Table 1. Effect of silicon priming on final germination percentage (FGP) and mean germination time (MGT).

\begin{tabular}{lll}
\hline Priming/ treatment & FGP & MGT \\
\hline Water (Control) & 78 & 1.6 \\
Silica gel 1\% & 93 & 1.4 \\
Silica gel 2\% & 99 & 1.2 \\
Sodium silicate 1\% & 98 & 1.2 \\
Sodium silicate 2\% & 75 & 1.6 \\
\hline
\end{tabular}

Growth of seedlings from silicon primed and hydroprimed seeds were measured in terms of chlorophyll content, root and shoot length, root and shoot fresh and dry weights. In salt stress, photosynthesis and photosynthetic pigments (chlorophyll content) were affected severely and these were mainly responsible for reduced plant growth and productivity. Results of the present work showed that in non saline conditions, the highest chlorophyll content was of silica gel $2 \%$ and the lowest was of silica gel $1 \%$. In saline conditions maximum values of chlorophyll content were of sodium silicate $1 \%$ and lowest were of control (Fig. 1). The findings of the present study was supported by experimental observations of Ali et al. (2013), who showed that application of silicon increased the chlorophyll content up to $8 \%$ in well-watered conditions and $13 \%$ in drought condition as compared to treatments without silicon application. The findings of present work was also very similar to research conclusion of Mushtaq et al. (2017) who found that in hydroponically grown wheat, chlorophyll contents of leaves which were affected by salt stress, increased significantly by silica nanoparticles priming.

Root and shoot lengths are important parameter for measuring growth of plants in salt stress. The results of current research revealed that maximum root length in non saline and saline treatment was of control and sodium silicate $2 \%$, while minimum root length was of sodium silicate $1 \%$ and control, respectively (Fig. 2). Whereas maximum shoot length in non saline and saline conditions was of seeds primed with sodium silicate $2 \%$ and sodium silicate $1 \%$, respectively and minimum shoot length were of hydropriming in both the conditions (Fig. 4). The 


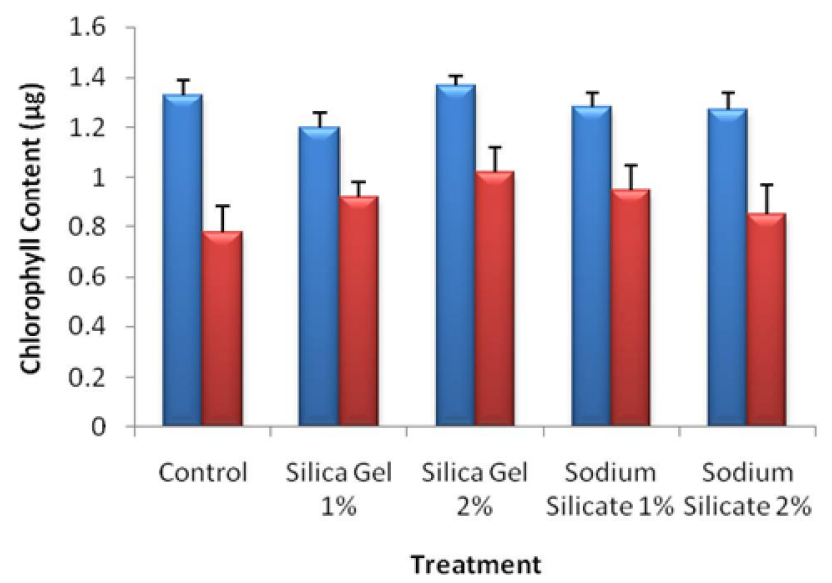

Fig. 1. Effect of priming with different silicon sources on chlorophyll content in saline (red bars) and non saline (blue bars) conditions.

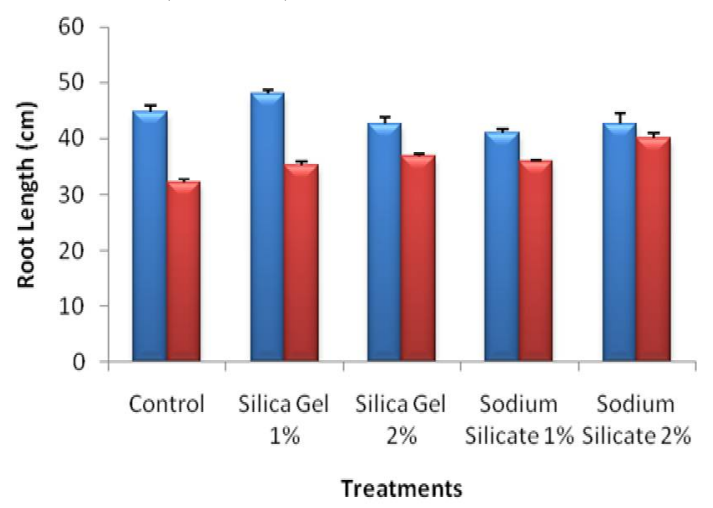

Fig. 2. Effect of priming with different silicon sources on root length (RL) in saline (red bars) and non saline (blue bars) conditions.

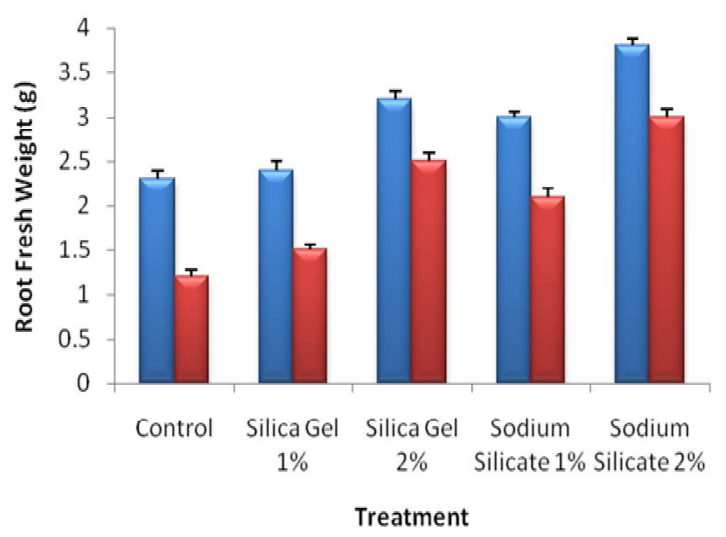

Fig. 3. Effect of priming with different silicon sources on root fresh weight (RFW) in saline (red bars) and non saline (blue bars) conditions. 
findings of the present work was supported by experimental conclusion of Mushtaq et al. (2017) that in hydroponically grown wheat seedlings, the root and shoot length effected by salt stress in control (hydropriming) showed remarkable increase by silica nanoparticles priming treatments. The outcomes of the present findings were in strong agreement to experimental results reported by Hameed et al. (2013) that under water deficit stress, priming of seeds with sodium silicate increase the root and shoot length of wheat, while hydropriming treatments to some extent increased root length but it could not improve the shoot length of seedling under water deficit stress.

High salinity levels stress the plants by ion toxicity and water deficiency that results in stunted growth and reduce root and shoot fresh and dry weights of plants (Hussain et al. 2013). The results of the present study revealed RFW of seedlings from hydroprimed seeds was lowest, while sodium silicate $2 \%$ primed seeds have the highest seedling's RFW in both non saline and saline treatments (Fig. 3). Differences between root dry weight among treatments was although very little but results showed that sodium silicate $2 \%$ and silica gel $2 \%$ showed best results, while control had the lowest values of RDW in both saline and non saline conditions. In both the conditions, maximum SFW and SDW were of sodium silicate $2 \%$ and minimum was of control (Fig. 5). The outcome of present work was also supported by experimental findings of Ali et al. (2013) that silicon induced stress tolerance in wheat hydroponically grown under water deficit conditions.

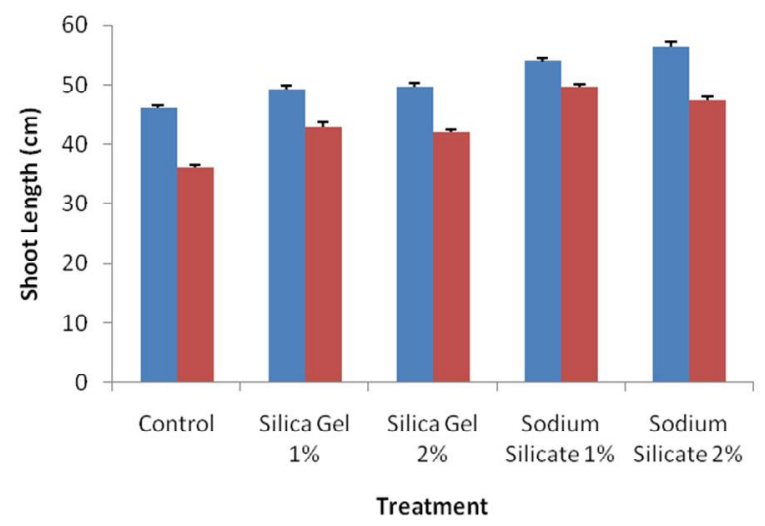

Fig. 4. Effect of priming with different silicon sources on shoot length (SL) in saline (red bars) and non saline (blue bars) conditions.

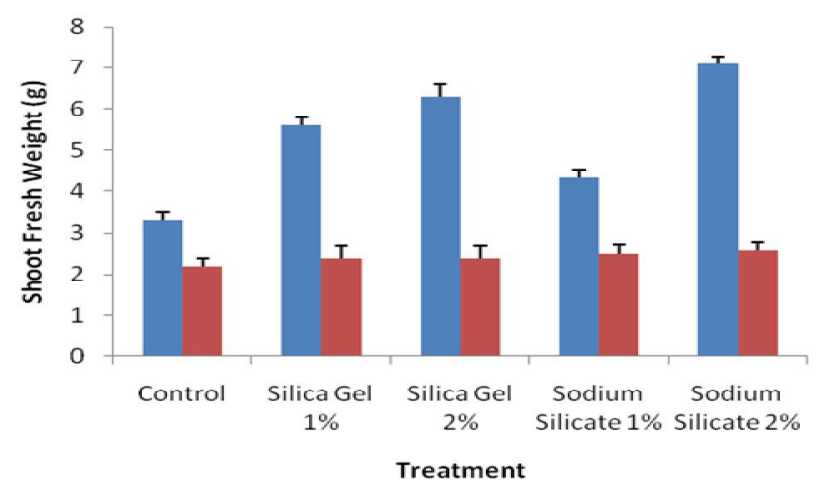

Fig. 5. Effect of priming with different silicon sources on shoot fresh weight (SFW) in saline (red bars) and non saline (blue bars) conditions. 
Results showed that in both well watered and drought conditions maximum seedlings (fresh and dry weight) where silicon was applied and without silicon applications least fresh and dry weight of seedlings was observed. The results of present study were similar to experimental outcome of Azimi et al. (2014) that seed prechilling with silica nanoparticles increased dry weight of shoot, root and seedling of tall wheatgrass.

Seedlings from silicon primed seeds were found to persist salinity to a greater extent than hydroprimed seeds. The study also helped to select more better source of silicon (sodium silicate) as it was a soluble silicon compound and was more efficiently converted into orthosilicic acid and then available to plants. Whereas silica gel is stable in neutral and alkaline solutions, but forms silicic acid in acidic solution and is then available to plants (Gocke et al. 2013). Out of two levels of silicon concentration ( 1 and $2 \%$ ), concentration of $2 \%$ was more effective against salinity, which was also supported by Azimi et al. (2014). Thus overall study depicts that priming of seeds with silicon sources (silica gel and sodium silicate) was an effective method for inducing tolerance to salinity as compared to hydropriming treatment.

\section{Acknowledgements}

The authors acknowledge the financial support of BEEF association and HEC, Pakistan. Also special thanks to SBKWU and BUITEMS Quetta for providing the facilities to conduct the study.

\section{References}

Afzal I, Basra SM, Farooq M and Nawaz A 2006. Alleviation of salinity stress in spring wheat by hormonal priming with ABA, salicylic acid and ascorbic acid. Int. J. Agri. Biol. 8: 23-28.

Afzal I, Basra SMA, Ahmad N and Lodhi TE 2007. Counteraction of salinity stress on wheat plants by presowing seed treatments. Pakistan J. Agri. Sci. 44: 50-58.

Ahmed M, Qadeer U, Ahmed ZI and Hassan F 2016. Improvement of wheat (Triticum aestivum) drought tolerance by seed priming with silicon. Archives of Agron. and Soil Sci. 62: 299-315.

Ali A, Tahir M, Amin M, Basra SMA, Maqbool M and Lee JD 2013. Si induced stress tolerance in wheat (Triticum aestivum L.) hydroponically grown under water deficit conditions. Bulgarian J. Agri. Sci. 19: 952-958.

Azimi R, Borzelabad MJ, Feizi $\mathrm{H}$ and Azimi A 2014. Interaction of $\mathrm{SiO}_{2}$ nanoparticles with seed prechilling on germination and early seedling growth of tall wheatgrass (Agropyron elongatum L.). Polish J. Chem. Technol. 16: 25-29.

Dianati TGA and Behtari B 2017. Alleviation of ionic and osmotic stress of salinity in seedling emergence of Lolium perenne L. with halopriming treatments growing in an hydroponic system. J. Plant Nutri. 40: 219-226.

Gocke M, Liang W, Sommer M and Kuzyakov Y 2013. Silicon uptake by wheat: Effects of Si pools and pH. J. Plant Nutrition and Soil Sci. 176: 551-560.

Hameed A, Sheikh MA, Jamil A and Basra SMA 2013. Seed priming with sodium silicate enhances seed germination and seedling growth in wheat (Triticum aestivum L.) under water deficit stress induced by polyethylene glycol. Pak. J. Life Soc. Sci. 11: 19-24.

Jahangir K, Saifullah K, Khetran MAKA, Sadiq N, Islam M, Hanan A and Aziz A 2013. Tijaban-10A drought tolerant and high yielding wheat variety for rainfed/sailaba areas of Balochistan. Pak. J. Bot. 45: 1357-1362.

Jamal Y, Shafi M and Arif M 2011. Seed priming improves salinity tolerance of wheat varieties. Pak. J. Bot. 43: $2683-2686$.

Maghsoudi K, Emam Y and Pessarakli M 2016. Effect of silicon on photosynthetic gas exchange, photosynthetic pigments, cell membrane stability and relative water content of different wheat cultivars under drought stress conditions. J. Plant Nutri. 39: 1001-1015. 
Mukhtar A, Umara Q, Zammurad IA and Fayyaz-ul H 2016. Improvement of Triticum aestivum drought tolerance by seed priming with silicon. Archives Agro. and Soil Sci. 62: 299-315.

Munns R and Tester M 2008. Mechanisms of salinity tolerance. Ann. Rev. Plant Biol. 59: 651-681.

Mushtaq A, Jamil N, Riaz M, Hornyak G, Ahmed N, Ahmed SS, Shahwani MN and Malghani MNK 2017. Synthesis of silica nanoparticles and their effect on priming of wheat (Triticum aestivum L.) under salinity stress. Biological Forum - An Int. J. 9: 150-157.

Solatni Z, Shekari F, Jamshidi K, Fotovat R and Azimkhani R 2012. The effect of silicon on germination and some growth characteristics of salt-stressed canola seedling. Int. J. Agron. Agric Res. 2: 12-21.

Yildirim M, Kizilgeci F, Akinci C and Albayrak O 2015. Response of durum wheat seedlings to salinity. Notulae Botanicae Horti Agrobotanici Cluj-Napoca. 43: 108-112.

(Manuscript received on 13 October, 2018; revised on 17 January, 2019) 